\title{
DINÂMICA POPULACIONAL DE COLÔNIAS DE $A P I S$ MELLIFERA DURANTE O PERÍODO CHUVOSO NA REGIÃO DE ARAGUAÍNA
}

Population dynamics of colonies of Apis mellifera during the rainy season in the region of Araguaína

Dinámica de la población de las colonias de Apis mellifera durante la temporada de lluvias en la región de Araguaína

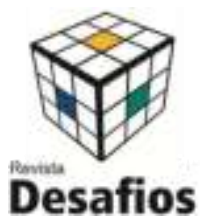

\section{Danielle Sales Ramalho-Sousa ${ }^{1}$, Daniel Henrique Souza Tavares ${ }^{1}$, Felipe de Lima Rosa ${ }^{1}$, Luciano Fernandes Sousa ${ }^{1}$, Rômulo Augusto Guedes Rizzardo ${ }^{* 1}$}

${ }^{1}$ Curso de Graduação em Zootecnia, Escola de Medicina Veterinária e Zootecnia, Universidade Federal do

Tocantins, Araguaína - TO, Brasil.

*Correspondência: Laboratório de Abelhas, Universidade Federal do Tocantins - EMVZ, BR-153, km 12, s/n-

Zona Rural de Araguaína, Araguaína,Tocantins, Brasil.CEP:77.804-970.e-mail rizzardo@uft.edu.br.

Artigo recebido em 30/10/2015. Aprovado em 09/12/2015. Publicado em 24/02/2017.

\section{RESUMO}

Este trabalho foi conduzido com o objetivo de acompanhar a dinâmica populacional de colônias de abelhas melíferas, durante o período chuvoso, na região de Araguaína e, como esse regime hídrico interfere na manutenção da colônia e organização social destes insetos. Foram avaliadas 4 colônias, alojadas em colmeias padrão Langstroth, entre setembro de 2013 e junho de 2014, quanto à área total dos quadros da colmeia ocupada por mel, pólen, cria de abelhas operárias, cria de zangões e por favos vazios. Observou-se que houve oscilação na área de mel entre os meses de outubro e abril, mostrando consumo das reservas de mel no período crítico, pois nesse período chuvoso, para se manterem e manterem as crias, as abelhas precisam de fonte energética. A produção de crias de zangões indica que a colônia está suprindo suas necessidades básicas. No mês de abril, por fragilidade da colônia, a produção de zangão foi zero. Foi possível perceber que as abelhas mantiveram suas colônias fortes praticamente todo ano, com redução apenas em abril, concluindo-se que com estoque de alimentos na colmeia, as colônias conseguem sobreviver mesmo com oscilações climáticas, indicando que a região de Araguaína é apta para apicultura.

Palavras-chave: Apicultura, manejo de abelhas melíferas, produção apícola.

\section{ABSTRACT}

This work was conducted with the objective of monitoring a population dynamics of honeybee colonies during the rainy season in the region of Araguaina and how this water regime interferes in the maintenance of the colony and social organization of these insects. Were evaluated four Langstroth hives, colonized with colonies of honeybees, during the period between September 2014 and June 2014, the nest frames filled by area occupied with honey, pollen, breed of worker bees, breed of drones and by empty combs. It was observed that there was oscillation in the area of honey in the month of October to April showing the consumption of honey reserves in the critical period, since there is no time to remain as breed, as bees need an energy source. After April, there was an increase in the breed area, indicating that the colony became nourished, already in April by the fragility of the colony, the production of drones was zero. It was possible to notice that the bees maintained their strong colonies practically every year, with reduction only in April, concluding that with food stocks in the beehive, as colonies can remain constant with climatic oscillations, indicating that the region of Araguaina suitable for Beekeeping. 
Keywords: beekeeping, honeybee handling, Beekeeping production.

\section{RESUMEN}

Este trabajo se llevó a cabo para controlar la dinámica poblacional de las colonias de abejas, durante la temporada de lluvias en la región de Araguaína y ya que este régimen de agua interfiere con el mantenimiento de la colonia y la organización social de estos insectos. Se evaluaron 4 colonias, que viven en colmenas tipo Langstroth, entre septiembre de 2013 y junio de 2014, en relación a área total de los panales de la colmena ocupados por la miel, el polen, las crías de abejas obreras, las crías de zángano y panales vacíos. Se observó que había una variación en el área de miel ente los meses de octubre y abril, que muestra el consumo de las reservas de miel en el período crítico, ya que esta temporada de lluvias para quedarse y mantener las crías, las abejas necesitan fuente de energía. La producción de crías de zánganos indica que la colonia está cumpliendo con sus necesidades básicas. En abril, por la fragilidad de la colonia, la producción de zánganos fue cero. Se pudo observar que las abejas mantienen sus colonias fuertes casi todo el año, con una reducción sólo en abril, concluyendo que con las reservas de alimentos en la colmena, la colonia puede sobrevivir incluso con oscilaciones climáticas, lo que indica que la región de Araguaína es adecuado para la apicultura.

Descriptores: Apicultura, Manejo de abejas, production de las abejas.

\section{INTRODUÇÃO}

A apicultura brasileira começou oficialmente em 1839, quando o padre Antonio Carneiro importou da região do Porto, Portugal, 100 colônias de abelhas da espécie Apis mellifera. No entanto, até a década de 1950, o Brasil produzia cerca de quatro mil toneladas de mel por ano (WIESE, 2005). Alguns anos após o advento da africanização houve aumento na produção devido a possibilidade de trabalhar com apicultura em todo o território brasileiro, atingindo em 2004, a $5^{\mathrm{a}}$ posição entre os exportadores de mel, com mais de 20 mil toneladas/ano (PAULA FILHO, 2007). A criação racional de abelhas representa importante atividade comercial, pois traz benefícios ao ser humano através de seus produtos utilizados para fins alimentícios, cosméticos e fármacos. Além disso, as abelhas realizam a polinização, processo necessário para a reprodução, disseminação das espécies vegetais e, principalmente produção de alimentos, aumentando a produtividade em cultivos agrícolas (GALLAI et al., 2009; RIZZARDO et al., 2012; GARIBALDI et al., 2013).
A apicultura depende diretamente de recursos naturais, e possui oscilação de produção de acordo com a variação climática de cada região (WIESE, 2005). A produção de pólen e néctar é influenciada pelo regime de chuvas, já que é o principal fator que determina a existência de floradas (Roubik, 1989). O clima e a disponibilidade de alimento numa região também têm influência sobre as características produtivas e reprodutivas nas colônias de abelhas, sendo possível observar que a produção de mel oscila de acordo com variáveis como temperatura, pluviosidade e floração (YAMAMOTO; AKATSU; SOARES, 2007; COSTA et. al, 2007; PEREIRA, 2006). Em condições de alta pluviosidade, o aporte de alimentos poderá ser menor que o consumo, isso porque as operárias não costumam sair da colônia durante as chuvas, devido à impossibilidade de voar como também ao encharcamento das flores. Por conta disto, os estoques de alimentos diminuem e a rainha diminui também a postura (OLIVEIRA e CUNHA, 2005).

Em regiões de clima tropical úmido, nas chamadas terras baixas e nas florestas do tipo 
ombrófila, as abelhas melíferas de raças europeias não apresentam êxito na produção de mel. Pelo contrário, apresentam-se fracas e são acometidas por doenças microbianas e fungícas, são pilhadas por formiga, outras abelhas e vespas, ou são destruídas por vertebrados predadores de ninho (ROUBIK, 1989).

A presença de crias é um dos fatores que reduzem o estímulo ao abandono do ninho, no entanto, aumentam as dificuldades para que sejam alimentadas, ficando estas mal nutridas e sujeitas a doenças, favorecendo, por exemplo, o desenvolvimento de traças, florídeos, ácaros e fungos (OLIVEIRA e CUNHA, 2005).

$\mathrm{Na}$ região Centro Norte do estado do Tocantins, tendo como referência a cidade de Araguaína, é possível encontrar vegetação de transição, sendo caracterizada como ecótono Cerrado Amazônia. Nesta área de sobreposição de biomas, suspeita-se que haja dificuldade para a sobrevivência da Apis mellifera, devido a condições climáticas desfavoráveis na época das águas. Com muita chuva e umidade elevada afetando a coleta de recursos florais, principalmente o pólen, base para a produção e desenvolvimento das crias, acredita-se que possa ser fator limitante para a apicultura nesta região (WIESE, 2005).

O trabalho foi conduzido com o objetivo de acompanhar a dinâmica populacional de colônias de Apis melífera durante o período chuvoso na região de Araguaína, área inclusa como Amazônia Legal, e como esse regime hídrico interfere na manutenção da colônia e organização social destes insetos.

\section{MATERIAIS E MÉTODOS}

O experimento foi conduzido no apiário da Escola de Medicina Veterinária e Zootecnia (EMVZ) da Universidade Federal do Tocantins (UFT), no município de Araguaína, região Norte do Tocantins, 07'11'28', de Latitude Sul, e $48^{\circ} 12$ '26' de Longitude Oeste, distante $400 \mathrm{~km}$ da capital, Palmas. O apiário é circundado por vegetação nativa, com pelo menos 1.000ha. Foram utilizadas quatro colmeias Langstroth, povoadas com colônias de Apis mellifera. Estas foram homogeneizadas quanto a condição nutricional e sanitária. Durante o período compreendido entre setembro de 2013 e junho de 2014 foram capturadas imagens em câmera digital Nikon Coolpix L110, dos quadros de ninho preenchidos por área ocupada por mel, por crias de abelhas operárias (Crias 2n), por crias de zangões (Crias n) e por favos vazios, a intervalos variados entre um e dois meses, em função do desenvolvimento histórico das abelhas nas épocas seca e chuvosa. Todas as colmeias receberam uma melgueira vazia no início do experimento e não foram feitas colheitas de mel, para evitar que esta variável interferisse na avaliação dos parâmetros deste trabalho. Os dados foram analisados de acordo com a numeração dos quadros para organizar a sequência das fotos registrando os dois lados de cada quadro (lados A e B). As fotos foram tiradas pelo período da manhã, entre 7:00 h e 11:30 h. A avaliação da área ocupada com cada variável é realizada através do mapeamento dos quadros, utilizando como ferramenta o programa Odo Plus para se fazer a contagem da área ocupada por mel, por crias de abelhas operárias (Crias 2n), por crias de zangões (Crias n) e por favos vazio. Para tabulação dos dados, foram utilizadas as planilhas eletrônicas do pacote $\mathrm{Br}$ office ${ }^{\circledR}$ (BRASIL, 2010). Os dados climáticos de umidade relativa média ar e precipitação pluviométrica foram coletados na estação meteorológica que fica na própria EMVZ, distante $500 \mathrm{~m}$ do apiário. O experimento contou com delineamento inteiramente casualizado, sendo a colmeia uma unidade experimental, totalizando 28 
repetições. Os dados foram submetidos a análise de normalidade pelo teste de Shapiro-Wilk e homogeneidade de variância pelo teste de Bartlett. Após satisfeitas essas pressuposições os dados foram submetidos a análise de variância e as médias comparadas pelo teste de Tukey, a 5,0\% de probabilidade.

\section{RESULTADOS E DISCUSSÃO}

Em função dos dados obtidos neste experimento, é possível analisar que as abelhas mantem suas colônias fortes durante praticamente todo o ano, sofrendo redução apenas no mês de abril, quando há o reflexo de todo o período chuvoso (Tabela 1). Neste trabalho foi possível perceber redução das colônias de abelhas no período observado como crítico, chuvoso, principalmente ao seu final, mês de abril, quando as abelhas praticamente esgotam suas reservas e a rainha diminui a postura. Mesmo com a diminuição das reservas, não foi verificado o esgotamento dos estoques tanto de pólen quanto de mel, favorecendo a permanência das colônias. Como não houve coleta de mel e pólen, períodos de menor oferta de alimento não foram sentidos pelas abelhas, indicando que estas podem sobreviver satisfatoriamente na região de Araguaína, com muita reserva de alimento. De acordo com a Tabela 1, é possível perceber que houve oscilação na área de mel, variando de $27.148,1 \mathrm{~cm}^{2}$ no mês de outubro para $7.295,9 \mathrm{~cm}^{2}$ no mês de abril, evidenciando claramente que, para as abelhas se manterem no período das águas, necessitam consumir suas reservar produzidas no período seco do ano (abril a outubro). Este fato aponta que, o apicultor interessado em manter a produtividade de suas colônias e evitar o abandono, deve conserva-las com reservas de alimento ou suprir, principalmente com fonte energética, suas colônias no período chuvoso. Outro ponto que serve como balizador do estado de desenvolvimento das colônias é a produção de zangões (cria n). Naturalmente como ocorre em grande parte dos animais, as colônias de abelhas só produzem zangões quando estão fortes e bem nutridas, dessa forma, a não produção de zangões no período de abril aponta fragilidade no desempenho das abelhas. Cabe ressaltar que, a manutenção do mel nas colônias deste experimento, pode ter estimulado a rápida progressão na área preenchida por esta variável. Com este aumento na produção, é possível inferir que ocorre produção e são fortes os indícios da viabilidade da apicultura na região de Araguaína, TO.

Tabela 1. Levantamento das áreas de mel, pólen, cria de operárias (2n), crias de zangão (n) e favos vazios, mensuradas por colmeia nos diferentes meses do ano. Araguaína, TO, 2014-2015.

\begin{tabular}{cccccccc}
\hline \multirow{2}{*}{$\begin{array}{c}\text { Var./ } \\
\text { Trat }\end{array}$} & \multirow{2}{*}{$\begin{array}{c}\text { Pluv. } \\
(\mathrm{mm} / \mathrm{mês})\end{array}$} & UR\% & \multicolumn{5}{c}{ Área em $\mathrm{cm}^{2}$ ocupada pelas variáveis na colméia } \\
\cline { 4 - 7 } & & & Mel & Pólen & Crias 2n & Crias n & Favos $\varnothing$ \\
\hline Ago & 14,7 & 51,67 & $17443,2 \mathrm{ab}$ & $1098,6 \mathrm{a}$ & $8254,4 \mathrm{ab}$ & $1646,2 \mathrm{a}$ & $7189,8 \mathrm{a}$ \\
Out & 161,5 & 71 & $27148,1 \mathrm{a}$ & $2476,3 \mathrm{a}$ & $5855,8 \mathrm{ab}$ & $530,6 \mathrm{a}$ & $6939,0 \mathrm{a}$ \\
Dez & 285 & 80,3 & $22904,0 \mathrm{ab}$ & $4812,8 \mathrm{a}$ & $6764,9 \mathrm{ab}$ & $143,6 \mathrm{a}$ & $8543,7 \mathrm{a}$ \\
Fev & 266,1 & 82,33 & $16765,8 \mathrm{abc}$ & $2834,2 \mathrm{a}$ & $9162,0 \mathrm{a}$ & $253,4 \mathrm{a}$ & $14148,1 \mathrm{ab}$ \\
Abr & 101,1 & 82,67 & $7295,9 \mathrm{c}$ & $6933,1 \mathrm{a}$ & $4148,7 \mathrm{~b}$ & 0 & $22770,2 \mathrm{~b}$
\end{tabular}




\section{CONCLUSÃO}

O regime hídrico interfere fortemente no desenvolvimento e manutenção das colônias de abelhas melíferas na região de Araguaína.

$\mathrm{Na}$ estação chuvosa, ocorre consumo das reservas de mel e pólen, pelas abelhas, na região de ecótono Cerrado Amazônia.

A época de poucas chuvas, caracterizado como período seco do ano, é propício ao desenvolvimento, acúmulo de alimento e produção de Apis mellifera.

É importante que o apicultor faça o monitoramento de suas colônias, principalmente no período chuvoso, a fim de evitar abandono das colmeias.

A região de Araguaína é apta à apicultura.

Todos os autores declararam não haver qualquer potencial conflito de interesses referente a este artigo.

\section{REFERÊNCIAS}

BRASIL, D.F. Verificação e análise da ambiência interna de colméias de abelhas (Apismellifera) relacionando ao manejo de troca e quadros com crias. 2010. Monografia (Graduação em Agronomia) Universidade Federal do Ceará, Fortaleza, 2010.

COSTA et al 2007. Desenvolvimento de colônias de abelhas Apis mellifera africanizadas na região de Maringá, Estado do Paraná. Acta scien, v.29, n. 1, p.101-108, 2007.

GALLAI， N.; SALLES， J.M.; SETTELE， J.; VAISSIÈRE, B.E. Economic valuation of the vulnerability of world agriculture confronted with pollinator decline. Ecological Economics, v. 68, n. 3, p. 810-821, 2009.

GARIBALDI， L.A.; STEFFAN-DEWENTER， I.; BARTOMEUS,I.; BENJAMIN, F.; BOREUX,V.; CARIVEAU, $\quad$ D.; $\quad$ CHACOFF,N.P.; DUDENHOFFER, J.H.; FREITAS, B.M.; GHAZOUL, J.; GREENLEAF, S.; HIPOLITO, J.; WINFFREE, R.; HOLZSCHUH, A.; HOWLETT, B.G. ISAACS, R.; JAVOREK, S.K.; KENNEDY, C.M.; KREWENKA， K.M.; KRISHNAN， S.; MANDELIK, Y.; MAYFIEL, M.M.; MOTZKE, I.; AIZEN, M.A.; MUNYULI, T.; NAULT, B.A.; OTIENO, M.; PETERSEN, J.; PISANTY, G.; POTTS, S.G.; RADER, R.; RICKETTS, T.H.; RUNDLOF, M.; SEYMOUR, C.L.; BOMMARCO, R.; SCHUEPP, C.; SZENTGYORGYI, H.; TAKI, H.; TSCHARNTKE，T.; VERGARA， C.H.; VIANA, B.F.; WANGER, T.C.; WESTPHAL， C.; WILLIAMS, N.; KLEIN, A.M.; CUNNINGHAM, S.A.; KREMEN， C.; CARVALHEIRO， L.G.; HARDER, L.D.; AFIK, O.; Wild Pollinators Enhance Fruit Set of Crops Regardless of Honey Bee Abundance. Science, v.339, n.1608, p.1608-1611, 2013.

OLIVEIRA, M.L.; CUNHA, J.A. Abelhas africanizadas Apis melíferas cutellata Lepeletier, 1836 (Hymenoptera: Apidae: Apinae) exploram recursos na floresta amazônica?. Acta Amazônia, v.35, n.3, 2005.

PAULA FILHO, J.F. de. Mel do Brasil: as exportações brasileiras de mel no período 2000/2006 e a contribuição do Sebrae. 2007. 66 f. Dissertação 
(Especialização)- Universidade Católica de Brasília, Brasília, DF, 2007.

ROUBIK, D.W. Ecology and natural history of tropical bees. Cambridge University Press: 1989.

PEREIRA, F.M.; FREITAS, B.M.; VIEIRA NETO, J.M.; LOPES, M.T.R.; BARBOSA, A.L.; CAMARGO, R.C.R.de. Desenvolvimento de colônias de abelhas com diferentes alimentos proteicos. Pesq. agropec. bras., Brasília, v.41, n.1, p.1-7, jan. 2006.

RIZZARDO, R.A.G; MILFONT, M.O; SILVA E.M.S; FREITAS B.M. Apis mellifera pollination improves agronomic productivity of anemophilous castor bean (Ricinus communis). Anais da Academia WIESE, H. Apicultura: Novos Tempos. 2.ed. Guaíba: Agrolivros. 2005.

YAMAMOTO, D. Y.; AKATSU, I. P.; SOARES, A. E. E. Quantificação da produção do mel de Scaptotrigonaaff. Depilis (hymenoptera, apidae, apinae) do município de Luiz Antônio, São Paulo, Brasil. Bioscience Journal, Uberlândia, v.23, n.1, p. 89-93, nov.2007.

Brasileira de Ciências, v.84, n.4, p.1137-1145, 2012. 